\title{
Design and Analysis of Split Fixture for Gear Hobbing Machine
}

\author{
Prajwal Shenoy ${ }^{1}$, Naik Nithesh $^{2 *}$, Manjunath Shettar ${ }^{2}$, Debarghya $^{2}$ and Wasim Abbas ${ }^{2}$ \\ ${ }^{1}$ Department of Mechatronics Engineering, Manipal Institute of Technology, Manipal Academy of \\ Higher Education, Manipal, India. \\ ${ }^{2}$ Department of Mechanical and Manufacturing Engineering, Manipal Institute of Technology, \\ Manipal Academy of Higher Education, Manipal, India.
}

\begin{abstract}
Compared to the conventional gear hobbing fixtures, split fixture can effectively reduce job set-up time during the manufacturing process. This paper investigates the behaviour and analysis of split fixture under varying static loading conditions. Design of the part was established by considering the ability of the split fixture to carry jobs of various diameters. In order to validate the design, Static structural analysis was carried out on two positional configurations of the split fixture. A load of 1 ton was applied on the resting face of the fixture to simulate the effect of holding the job. The analysis included a study of the Stress, Deformations, and Modal analysis at different resonating frequencies to check for failure of design. By applying varying loads similar to practical conditions, it was observed that the design successfully withstood the applied forces without failure and a factor of safety of 142 was achieved in a critical loading case. Investigating the effect of dynamic loads on the Split Fixture and including auxiliary assembly components in design analysis.
\end{abstract}

Keywords: Gear hobbing, Modal analysis, Split fixture, Static structural analysis

\section{Introduction}

Gear hobbing machine is used for machining and production of an external tooth form developed uniformly about a rotating center [1]. It is a relatively advanced form of machining. Specially designed fixtures are needed for gear hobbing. The design of fixture focuses on elimination of the movement of the workpiece undergoing machining process. Fixtures are generally designed for a specific operation and a given work piece individually. This increases the set up time, also adding to the labour cost and also wasting the company's money. To reduce the set up time without changing the fixtures for the different loads the design of split fixture was taken into consideration. Split fixture has a rotating screw which ensures the jaw expansion, thus reducing the setup time for the jobs of different diameter [2].

\footnotetext{
* Corresponding author: nithesh.naik@manipal.edu
} 


\section{Methodology}

\subsection{Design}

The Split fixture is modelled using modelling software Solid Works ${ }^{\circledR}$. The current design is derived from the combination of the fixture design and functionality of the currently used in gear hobbing machine which is widely used individually for different sized gears to be hobbed. The functional dimensions and attributes were considered to build the current prototype. The components of the developed design are listed as shown in Fig. 1:

1) Collar. 2) Job Resting section. 3) Ribs 4) Fixture structure plate. 5) Hand wheel.

6) Fixture base. 7) Extended slots 8) T Bar coupler 9) Sliding T bar. 10) Ball Screw Thread.

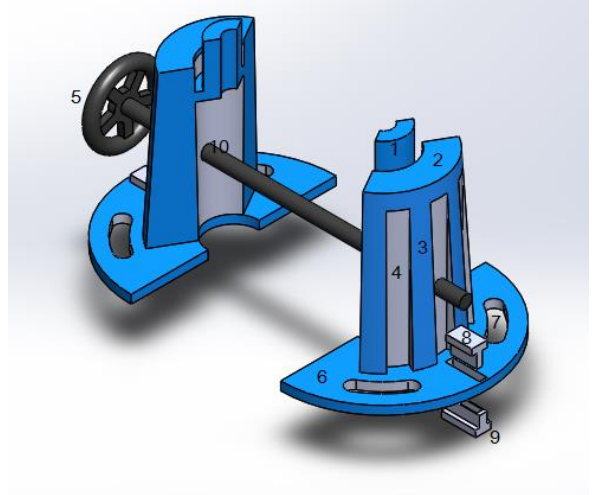

Fig. 1. Split Fixture Assembly

The split fixture we designed have certain manufacturing and dimensional considerations. It has a load carrying capacity of 1.5-2.5 tons. Ball screw thread is incorporated for easy alteration in the outside diameter of the fixture. [4] The prototype to be produced of Mild Steel 25HRC. The fixture is designed and analysed with two different center distances of $350 \mathrm{~mm}$ and $550 \mathrm{~mm}$ respectively. Also the height of the fixture from the fixture base to the job resting section is $360 \mathrm{~mm}$. There is a taper of 2 degrees of the fixture structure plate with the vertical. Sliding $\mathrm{T}$ bars are provided along worktable slots to slide the component manually and provided with a clearance of $1 \mathrm{~mm}$ along its edges. [3]
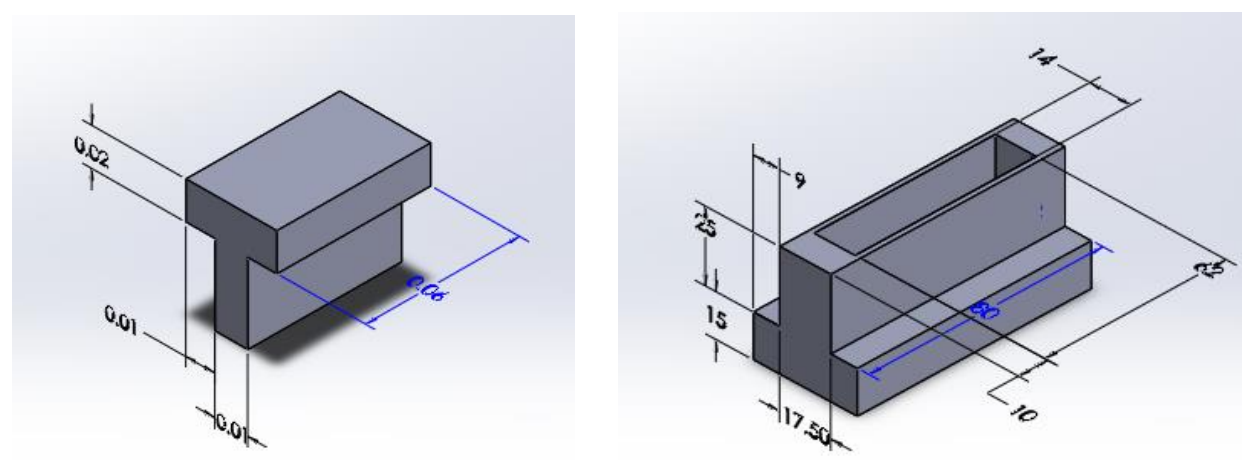

Fig. 2. T Bar and T Bar Coupler 
The Fig. 3 shows the split fixture assembly with dimensions. Two models were prepared with different dimensions, Model 1 - Fixture A had CC*-350mm, Height-390mm and resting face-70mm, followed by Model 2 - Fixture C which had CC-550mm, Height of $450 \mathrm{~mm}$ and the resting face of $75 \mathrm{~mm}$.

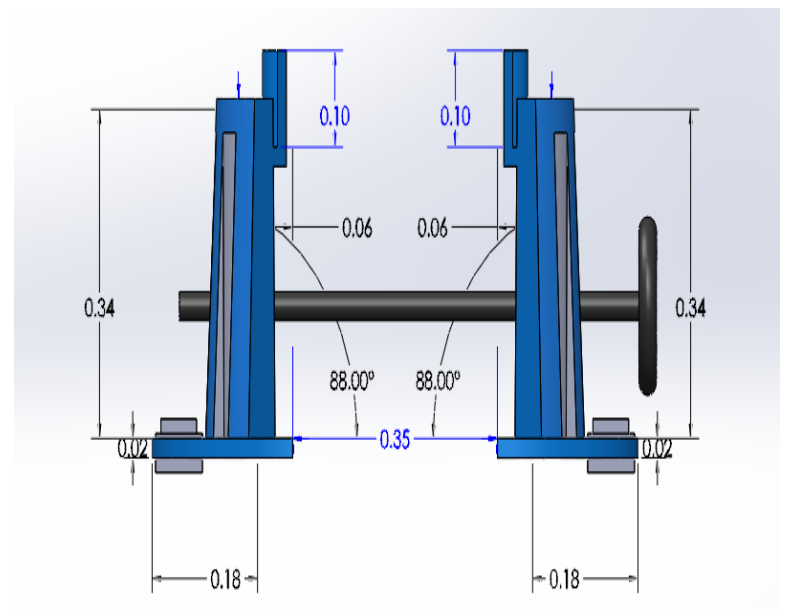

Fig. 3. Split Fixture A - Assembly Dimensions.

\subsection{Analysis}

The analysis of this split fixture was carried out using ANSYS Workbench Version 12.0. The meshing size is medium, and has a fine setting for proximity and Curvature. Analysis is carried out with a boundary condition of a fixed base (all DOF locked), whereas the topmost face, known as the Job resting face above has a pressure loading of 1tonne. The Modal analysis is being carried out considering the Fixture base as FIXED. The results being analysed involve the study of total deformations, Von Misses Stress, Modal analysis (first 5 frequencies). The underlying table gives a brief observation based on the analysis carried out. All the values enlisted in the table are the maximum values under the defined loading conditions. [5]

\section{Results and Discussions}

The Table 1 shows the results of total deformations, Von Mises stress and the five mode shapes of the Model 1 and Model 2 derived from modal analysis. The Model 1 and Model 2 with the centre distance of $350 \mathrm{~mm}$ and centre distance of $550 \mathrm{~mm}$ were selected based on the size of the gear to be hobbed. However the same fixture can be used for varying dimensions of centre distance over a range of $250 \mathrm{~mm}$ to $1000 \mathrm{~mm}$.

As shown in the Fig. 4 and Fig. 5 the analysis of the $350 \mathrm{~mm}$ configuration resulted in a maximum deformation of $0.001589 \mathrm{~m}$. The analysis of the $550 \mathrm{~mm}$ configuration resulted in a maximum deformation of $0.001589 \mathrm{~m}$. 
Table 1. Results of Total deformation, Stress and Modal Analysis of Model 1 and Model 2.

\begin{tabular}{|c|c|c|c|c|}
\hline $\begin{array}{c}\text { Analysed } \\
\text { Parameter }\end{array}$ & $\begin{array}{c}\text { Model 1 } \\
\text { Centre Distance } \\
550 \mathrm{~mm} \\
\text { Observations }\end{array}$ & $\begin{array}{c}\text { Model 2 } \\
\text { Centre Distance } \\
350 \mathrm{~mm} \\
\text { Observations }\end{array}$ & $\begin{array}{c}\text { Model 1 } \\
\text { Centre Distance } \\
550 \mathrm{~mm} \\
\text { Resonating } \\
\text { frequency }\end{array}$ & $\begin{array}{c}\text { Model 2 } \\
\text { Centre Distance } \\
350 \mathrm{~mm} \\
\text { Resonating } \\
\text { frequency }\end{array}$ \\
\hline $\begin{array}{c}\text { Von Mises Stress } \\
\text { Modal Analysis } \\
\text { Mode Shape 1 }\end{array}$ & $13.307 \mathrm{~mm}$ & $13.379 \mathrm{~mm}$ & $490.64 \mathrm{~Hz}$ & NIL \\
\hline $\begin{array}{c}\text { Modal Analysis } \\
\text { Mode Shape 1 }\end{array}$ & $13.31 \mathrm{~mm}$ & $13.381 \mathrm{~mm}$ & $490.65 \mathrm{~Hz}$ & $490.66 \mathrm{~Hz}$ \\
\hline $\begin{array}{c}\text { Modal Analysis } \\
\text { Mode Shape 1 }\end{array}$ & $12.096 \mathrm{~mm}$ & $12.309 \mathrm{~mm}$ & $1007.1 \mathrm{~Hz}$ & $1007.3 \mathrm{~Hz}$ \\
\hline $\begin{array}{c}\text { Modal Analysis } \\
\text { Mode Shape 1 }\end{array}$ & $12.096 \mathrm{~mm}$ & $12.312 \mathrm{~mm}$ & $1007.1 \mathrm{~Hz}$ & $1007.4 \mathrm{~Hz}$ \\
\hline $\begin{array}{c}\text { Modal Analysis } \\
\text { Mode Shape 1 }\end{array}$ & $38.748 \mathrm{~mm}$ & $38.744 \mathrm{~mm}$ & $1333.1 \mathrm{~Hz}$ & $1333.1 \mathrm{~Hz}$ \\
\hline
\end{tabular}

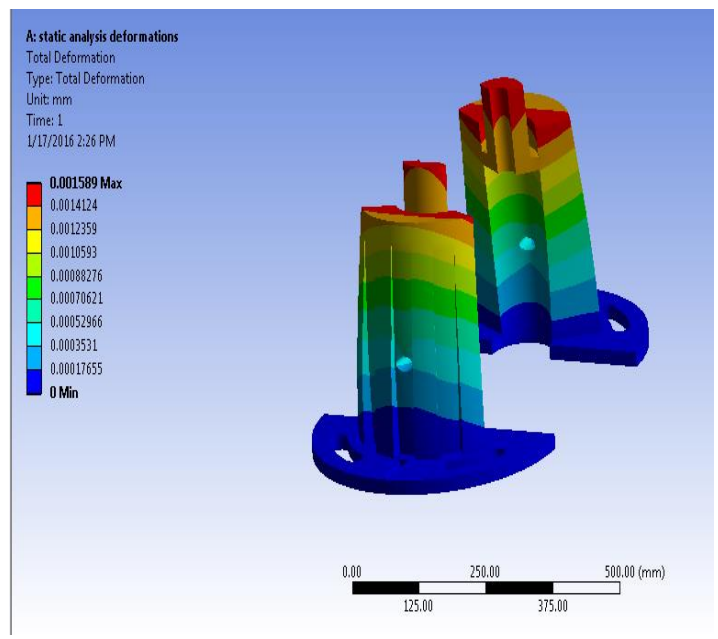

Fig. 4. Total Deformation (CC 350mm). 


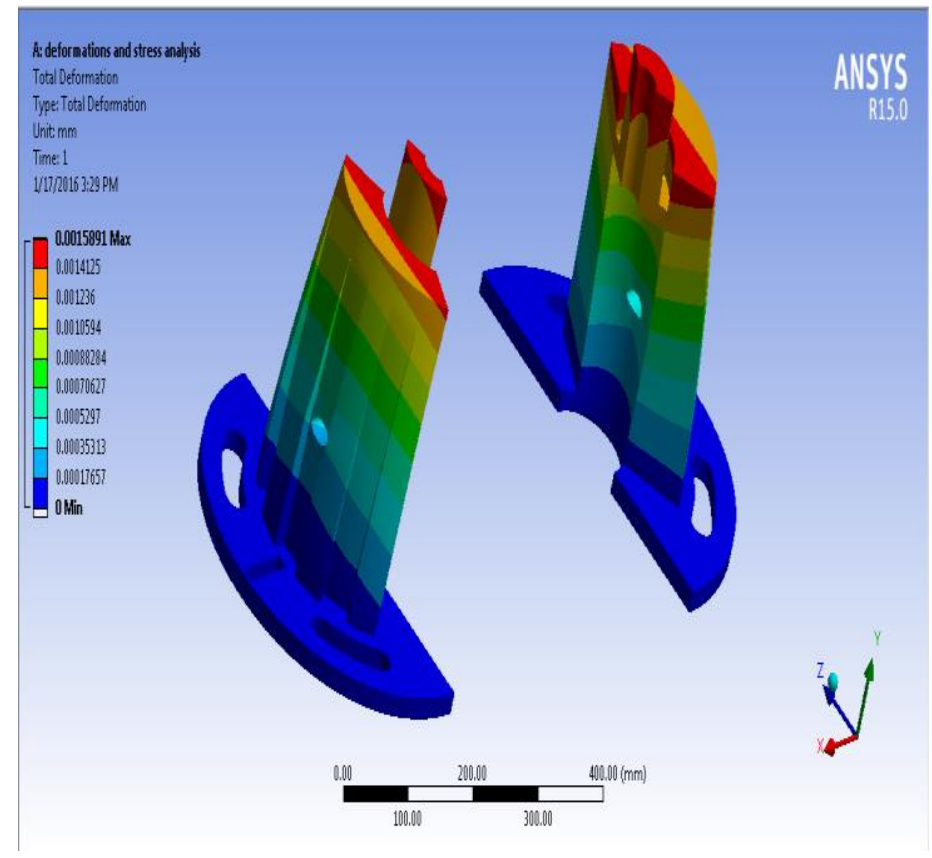

Fig. 5. Total Deformation (CC 550mm).

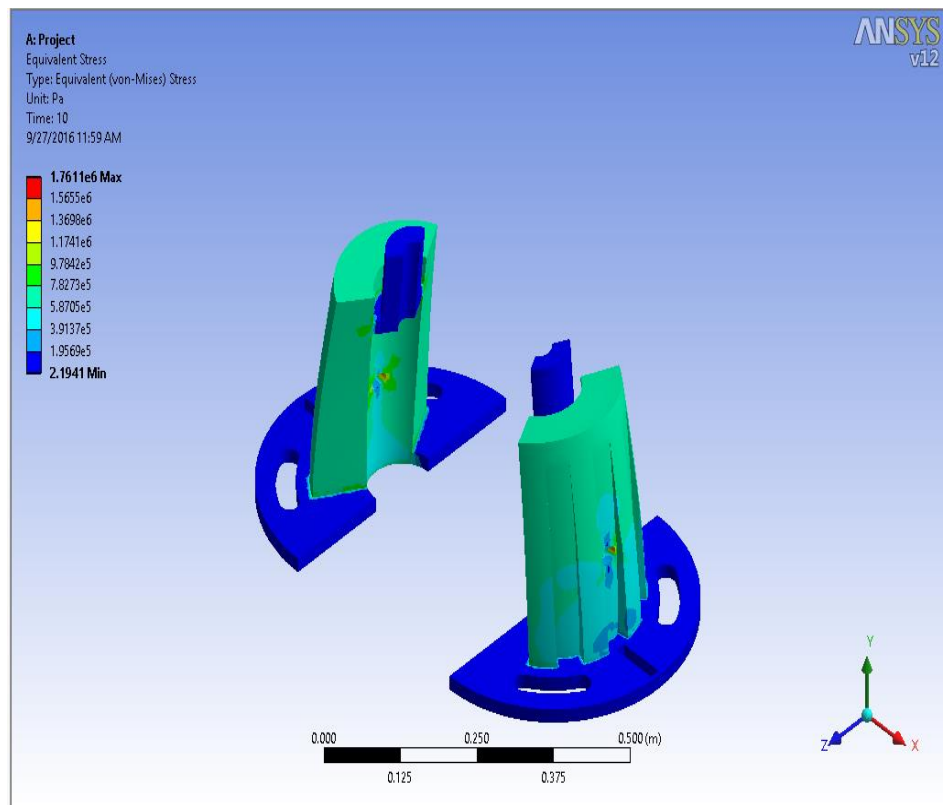

Fig. 6. Von-Misses Stress (CC 350mm).

The analysis of the $350 \mathrm{~mm}$ configuration resulted in a maximum Von-Misses stress of $1.7611 \mathrm{MPa}$, which is less than $250 \mathrm{MPa}$; the yield strength of Static Structural Steel (25HRC). 


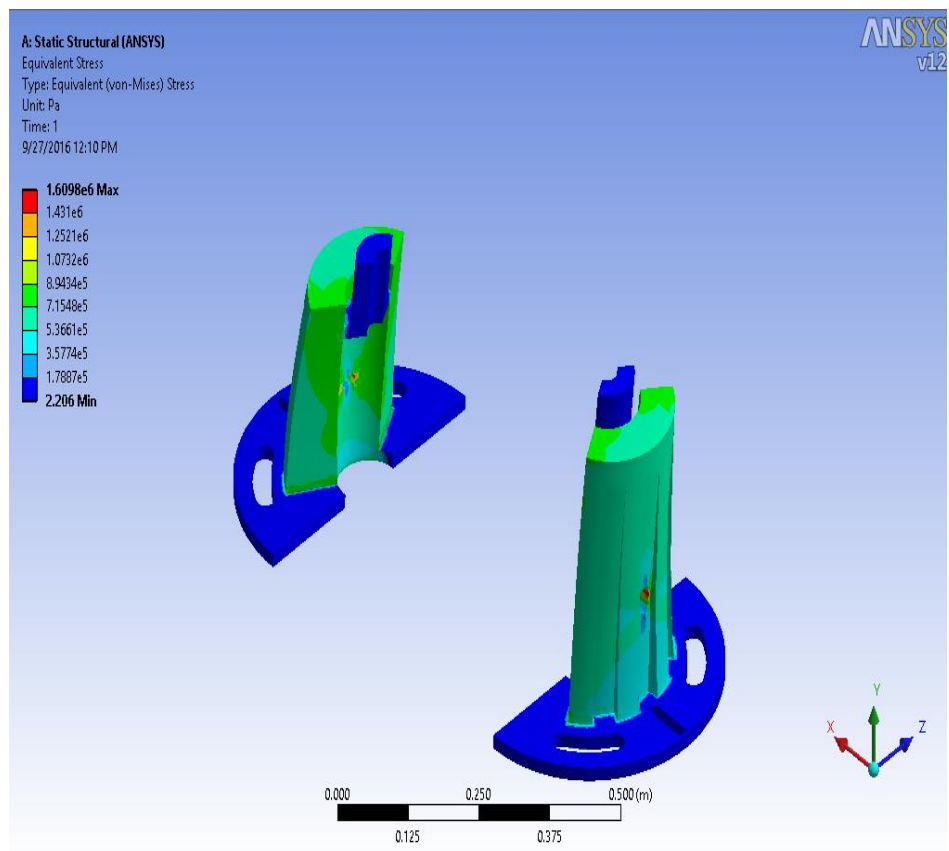

Fig. 7. Von-Misses Stress (CC 550mm).

The analysis of the $550 \mathrm{~mm}$ configuration resulted in a maximum Von-Misses stress of $1.6098 \mathrm{MPa}$, which is less than $250 \mathrm{MPa}$; the yield strength of Static Structural Steel (25HRC).

The plot of force v/s displacement is given below (Fig. 8 and Fig. 9). It can be observed from the linear nature of the curve that the stress values on the fixture lie within elastic limits and hence below the yield stress of Structural Steel (25HRC). [6]

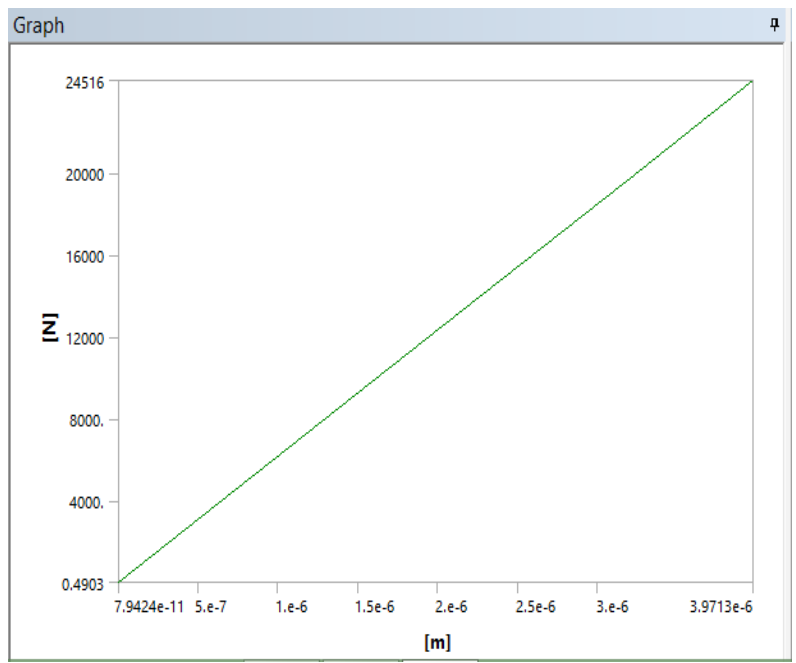

Fig. 8. Force v/s Deformation curve (CC 350mm). 


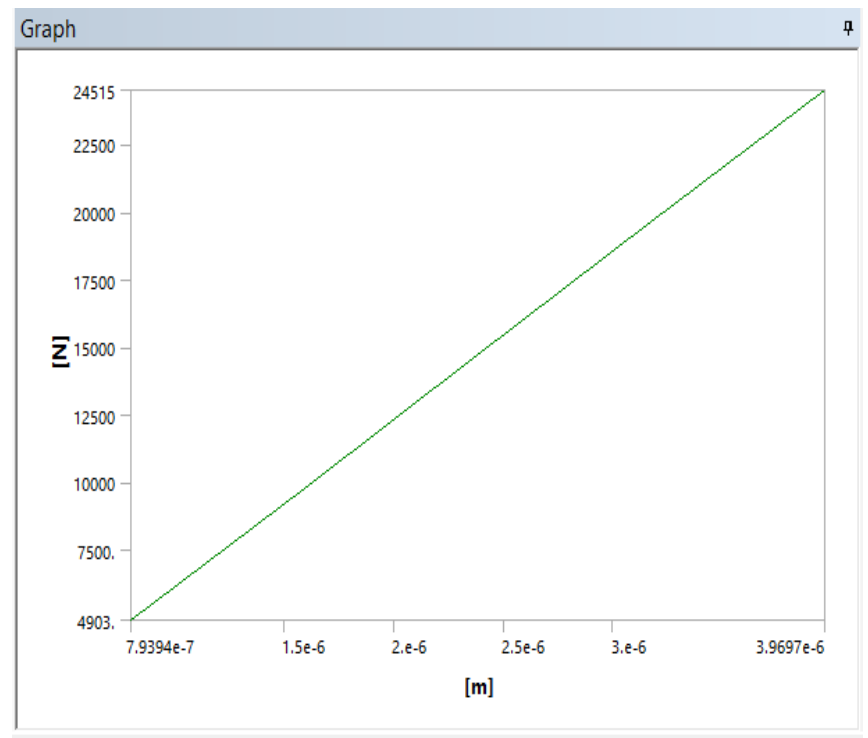

Fig. 9. Force v/s Deformation curve (CC 550mm).

\section{Conclusions}

The results derived through a simulation analysis considering the mechanical behaviour of the split fixture under uniformly distributed load of 1 Ton. The analysis was performed on two configurations of centre to center distance- (a) $350 \mathrm{~mm}$ and (b) $550 \mathrm{~mm}$.

-The split fixture design built is suitable to cater heavy loads as heavy as uniformly distributed load of 1 Ton.

-The fixture designed will cater to the wide range of diameter of the gear whose OD lies between $200 \mathrm{~mm}$ to $1000 \mathrm{~mm}$.

-The fixture designed will reduce the setup time hence reducing the overall manufacturing lead time of the gear production process.

-The above results show that designed structure lies within the acceptable limits of practical application and can be utilized for Industrial applications to reduce the set up time and increase the productivity.

The authors would like to be obliged to Department of Mechanical and Manufacturing. Engineering, Manipal Institute of Technology, Manipal Academy of Higher Education, for their extended support for providing lab and testing facility for the investigation

\section{References}

1. M. Yu Wang, P. Diana, CAD-based simulation of the hobbing process for the manufacturing of spur and helical gears, International Journal of Advanced Manufacturing and Technology, 347-357, (2009).

2. Karan Sharma, Naik Nithesh, Arun Prabhu, George Varghese, "Setup Time Reduction For CNC Hobbing Machine Implementing SMED And Design of "Split Fixture" International Journal of Mechanical And Production Engineering, ISSN: 2320-2092, Volume- 2, Issue-11, (2014). 
3. Rong Y, Bai Y, Machining accuracy analysis for computer aided fixture design verification. Journal of Manufacturing Science Engineering, 118, 289-300, (1996)

4. Cai W, Hu SJ et al, A Variation method of robust fixture configuration design for 3-D workpieces. Journal of Manufacturing Science Engineering, 119, 593-602, (1997).

5. Djurdjanovic D, Ni J, Dimensional errors of fixtures, locating and measurement datum features in the stream of variation modelling in machining. Journal of Manufacturing Science Engineering, Transactions of ASME, 125(4), 716-730, (2003).

6. K. Kim, M.K. Kim, Volumetric accuracy analysis based on generalized geometric error model in multi-axis machine tools, Mech. Mach. Theory, 26(2), 207-219, (1991). 